\title{
INFLUÊNCIA DA ESTAMPAGEM INCREMENTAL NA RUGOSIDADE E MOLHABILIDADE DE CHAPAS DE TI-CP*
}

\author{
Caroline Antunes Correa ${ }^{1}$ \\ Leonardo Marasca Antonini ${ }^{2}$ \\ Vinícius Kothe ${ }^{3}$ \\ Zigmunt Lucian Wislockit \\ Hugo Marcelo Veit ${ }^{6}$ \\ Jovani Castelan ${ }^{7}$ \\ Anderson Daleffe ${ }^{8}$ \\ Célia de Fraga Malfatti ${ }^{5}$
}

\section{Resumo}

Durante o processo por estampagem incremental, parâmetros como velocidade relativa, tamanho e material da ferramenta de estampagem, podem mudar as características superficiais do material. Para um biomaterial ser utilizado em implantes, um dos principais aspectos que pode influenciar sobre o processo de osseointegração são propriedades superficiais como rugosidade e molhabilidade. Nesse contexto, esse trabalho visa avaliar o efeito do processo de estampagem incremental seguido pelo tratamento térmico sobre a rugosidade e molhabilidade de chapas de Ti-cp com estampagem. A composição química e a morfologia das superfícies foram avaliadas por MEV/EDS. Resultados preliminares indicaram que a morfologia superficial é fortemente modificada pelo processo de estampagem incremental.

Palavras-chave: Estampagem Incremental; Molhabilidade; Biomaterial; Rugosidade.

\section{INFLUENCE OF THE INCREMENTAL SHEET FORMING ON ROUGHNESS AND WETTABILITY OF TI-CP SHEETS}

\section{Abstract}

During the incremental sheet forming process, parameters as relative velocity, size and material of the forming tool, can change the sheets surface characteristics. It is known that for biomaterials used in implants, one of the main aspects that can influence on the osseointegration processes is the surface characteristic, such as roughness and wettability. In this context, this work aims to evaluate the effect of incremental forming process followed by heat treatment on, roughness and wettability of shaped Ti-cp sheets. The chemical composition and the surface morphology of the systems were evaluated by SEM/EDS. The obtained results indicate that the surface morphology are strongly modified by the incremental forming process.

Keywords: Incremental sheet forming; Wettability; Biomaterial; Roughness.

1 Engenharia Metalúrgica, Graduanda, Estudante, Departamento de Metalurgia, Universidade Federal do Rio Grande do Sul (UFRGS), Porto Alegre, Rio Grande do Sul, Brasil.

2 Química Industrial, Doutorando em Engenharia de Minas, Metalúrgica e Materiais, Estudante, Departamento de Metalurgia, UFRGS, Porto Alegre, RS, Brasil.

3 Odontologia, Graduado, Estudante, Departamento de Metalurgia, UFRGS, Porto Alegre, RS, Brasil.

4 Engenharia Metalúrgica, Graduado, Estudante, Departamento de Metalurgia, Universidade Federal do Rio Grande do Sul, Porto Alegre, Rio Grande do Sul, Brasil.

5 Engenharia Metalúrgica, Doutor em Engenharia de Minas, Metalúrgica e de Materiais, Professora, Departamento de Metalurgia, UFRGS, Porto Alegre, RS, Brasil.

6 Licenciatura em Desenho, Doutor em Engenharia de Minas, Metalúrgica e de Materiais, Professor e Coordenador, Faculdade SATC, Criciúma, SC, Brasil.

7 Tecnologia em Eletromecânica, Doutor em Engenharia de Minas, Metalúrgica e de Materiais, Professor e Pesquisador, Faculdade SATC, Criciúma, SC, Brasil.

8 Engenharia Metalúrgica, Doutora em Engenharia de Minas, Metalúrgica e de Materiais, Professora, Departamento de Metalurgia, UFRGS, Porto Alegre, RS, Brasil. 


\section{INTRODUÇÃO}

O uso de metais e suas ligas em aplicações biomédicas tem sido crescente, muitos estudos têm investigado os melhores parâmetros operacionais para obter características que influenciam nas propriedades desses materiais, dentre esses parâmetros se destacam, a resistência à corrosão, biocompatibilidade, resistência mecânica e à fadiga. Dentre os metais biocompatíveis o titânio tem uma grande importância devido as suas características como uma alta resistência mecânica, baixa massa específica comparada a outros metais, alta resistência à corrosão e excelente biocompatibilidade $[1,2]$.

A fim de melhorar a osseointegração dos implantes de titânio, muitos estudos de modificação superficial têm sido de grande interesse, focando a importância das propriedades morfológicas e de composição química. Propriedades essas que diretamente influenciam no sucesso da biocompatibilidade, como a adesão celular e extracelular do implante durante a osseointegração [3]. Dentre esses parâmetros, estudos vêm demonstrando que o sucesso do implante é fortemente dependente da molhabilidade da superfície, e estudos têm indicado que superfícies com tendência hidrofílica favorecem a adesão do implante [4].

Características como a rugosidade da superfície são fundamentais para o processo de biointegração conforme mostrado por alguns estudos [5-7]. Propriedades celulares como adesão, alterações morfológicas, e proliferação são afetadas pela composição química, rugosidade e tensão superficial do material [8]. Essas características controlam a quantidade da adesão celular sobre o implante e consequentemente, sobre o crescimento do tecido. Dessa forma a etapa de caracterização da superfície do material é considerada um componente importante nos protocolos de fabricação e na avaliação do desempenho dos biomateriais [9]. Osteoblastos espraiam mais nas superfícies com baixa amplitude de rugosidade (reentrâncias mais rasas). No entanto mostraram uma alta força de adesão nas superfícies mais rugosas [10].

Em caso de implantes cranianos, esses devem se ajustar bem às características geométricas de cada paciente. A técnica de estampagem incremental de chapas na produção desses implantes apresenta algumas vantagens em relação aos outros métodos de conformação, como por exemplo: baixo custo, alta flexibilidade de produção e impacto ambiental e facilidade de produção de peças em pequena escala e sob medida. Esta última é a vantagem principal para implementação da técnica de estampagem incremental na produção de implantes cranianos [11].

\section{MATERIAIS E MÉTODOS}

A estampagem incremental foi realizada em um centro de usinagem Discovery D600, comando Fanuc e utilizou uma ferramenta de ponta esférica com diâmetro de contato de $10 \mathrm{~mm}$, com haste em aço 4340, e inserto de Ti-cp grau 2. Os dados tecnológicos foram: velocidade de avanço de $2.000 \mathrm{~mm} / \mathrm{min}$; rotação de $50 \mathrm{RPM}$ e incremento vertical de $1 \mathrm{~mm}$, havendo posterior tratamento térmico para alivio de tensões, em forno (sem atmosfera controlada), para uma das duas peças estampadas com geometria piramidal. O lubrificante utilizado foi uma graxa sintética composta por lítio.

$\mathrm{Na}$ região central das faces da peça foram retiradas amostras $\left(1,0 \mathrm{~cm}^{2}\right.$ e espessura em torno de 0,2 mm), no sentido longitudinal e transversal em relação à direção de laminação da chapa utilizada no processo de estampagem incremental. 
As amostras depois de recebidas, passaram por desengraxe e, uma solução neutra a $50^{\circ} \mathrm{C}$ e com agitação por 10 minutos sendo depois disso lavadas com álcool etílico e secas com ar frio.

As amostras indicadas com $\mathrm{L}$ correspondem o sentido longitudinal do contato da ferramenta de estampagem com o sentido de laminação da chapa; enquanto que a letra $\mathrm{T}$ corresponde ao sentido transversal ao sentido de laminação. A face interna das amostras é a face da amostra que entrou em contato com a ferramenta e o lubrificante durante o processo de estampagem incremental, enquanto que a face externa permaneceu sem contato com a ferramenta.

Amostras de $\mathrm{Ti}$-cp que passaram por tratamento térmico com rampa de aquecimento de 2 horas, 2 horas mantido a $400^{\circ} \mathrm{C}$ e resfriamento de 4 horas. Um perfilômetro de contato (CETR-PRO5003D) foi usado para determinar a rugosidade da superfície. Foram realizadas três medidas para cada amostra para determinar a rugosidade media $(\mathrm{Ra})$, rugosidade medida a partir da distância entre o pico mais alto e o vale mais profundo ( $\mathrm{Rt})$ e a rugosidade média quadrática ( $\mathrm{Rms})$. A molhabilidade da superfície foi determinada pelas medidas de ângulo de contato, entre a solução KOKUBO [12] e a superfície da amostra usando um aparato desenvolvido no LAPEC/UFRGS (Figura 1). O software de análise de imagem foi utilizado para determinar o ângulo de contato.

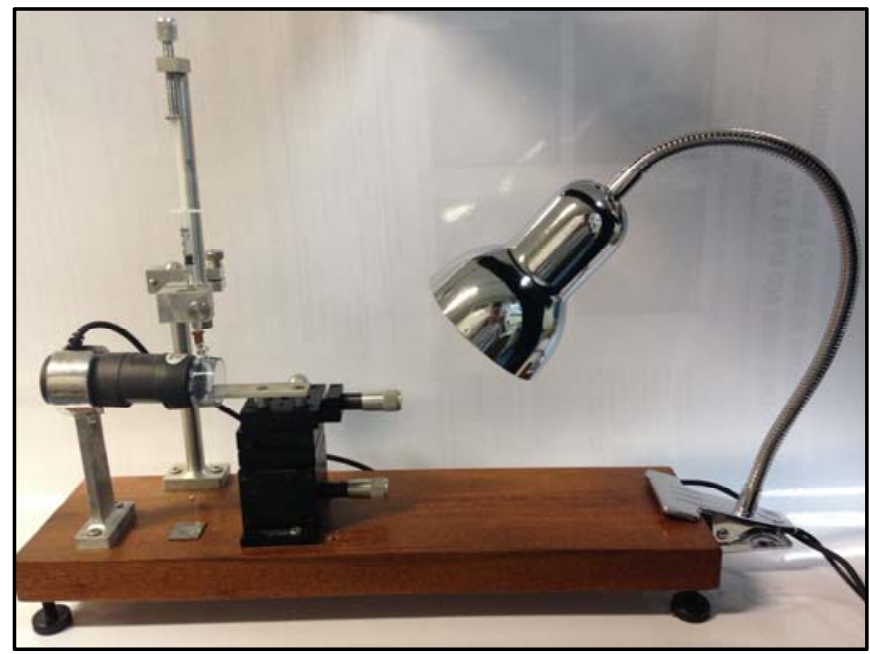

Figura 1. Foto do aparato desenvolvido no LAPEC/UFRGS para medidas do ângulo de contato.

A morfologia da superfície e a microestrutura por corte transversal das amostras foram analisadas por um microscópio óptico OLYMPUS CX31. A caracterização morfológica das amostras através do MEV e EDS foi realizada por meio de um microscópio eletrônico de varredura (MEV), modelo JSM 6510LV - marca JEOL aplicando $20 \mathrm{kV}$.

Estão apresentadas as peça em formato piramidal obtida por processo de estampagem incremental, sem (Figura 2) e com tratamento térmico (Figura 3). Amostras de Ti-cp grau 2 avaliadas no presente trabalho, estão descritas na Tabela 1. 
Tabela 1. Descrição das amostras para os sistemas avaliados.

\begin{tabular}{cccc}
\hline Amostras & \multicolumn{1}{c}{ Seção } & Face & Tratamento \\
\hline LSTTE & Longitudinal & Externa & \\
LSTTI & & Interna & \\
TSTTE & Transversal & Externa & Sem tratamento térmico \\
TSTTI & & Interna & \\
LCTTE & Longitudinal & Externa & \\
LCTTI & & Interna & \multirow{2}{*}{ Com tratamento térmico } \\
TCTTE & Transversal & Externa & \\
TCTTI & & Interna & \\
& & & \\
\hline
\end{tabular}

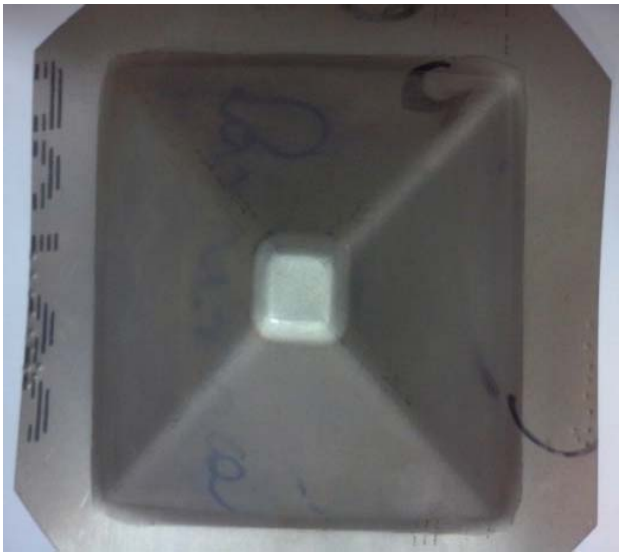

Figura 2. Chapa após estampagem incremental e sem tratamento térmico.

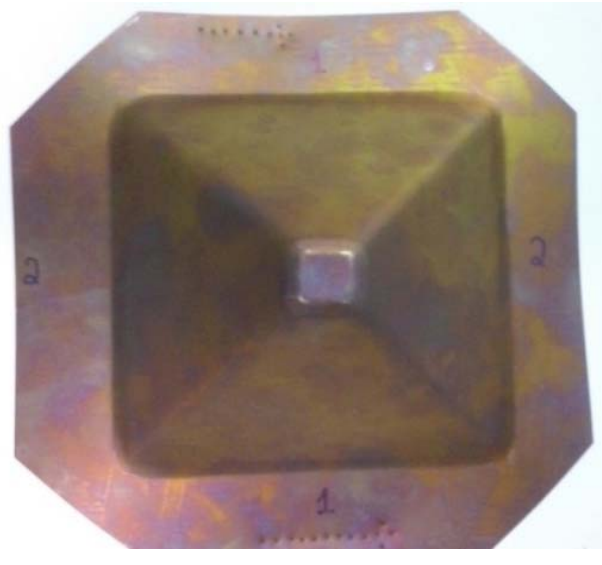

Figura 3. Chapa após estampagem incremental e posterior tratamento térmico.

\section{RESULTADOS E DISCUSSÃO}

A partir das análises por microscopia óptica das amostras em corte transversal (Figura 4), é possível observar que as amostras tratadas termicamente apresentaram a formação de uma provável camada de óxido, conforme já foi observado por outros autores [13].
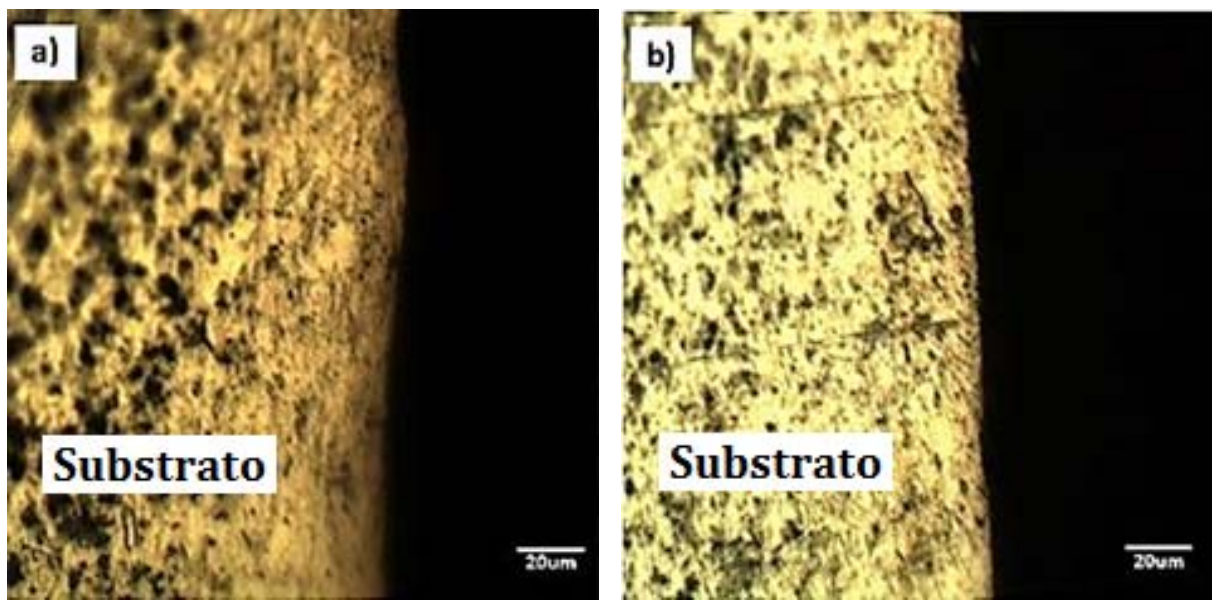

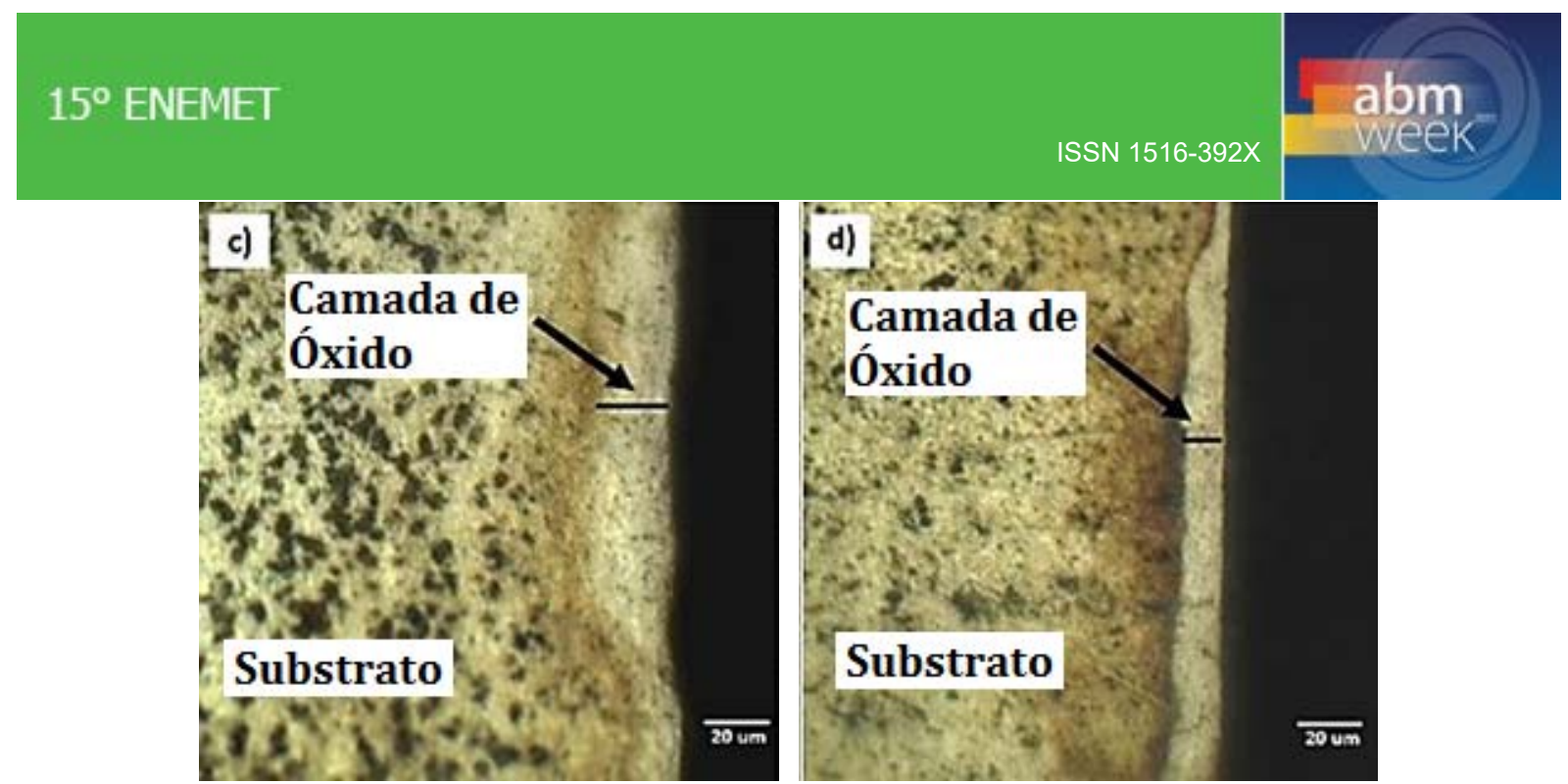

Figura 4. Imagens por Microscopia Óptica das amostras após estampagem incremental, sem tratamento térmico (a) LSTT, (b) TSTT e com tratamento térmico (c) LCTT e (d) TCTT.

A partir das imagens obtidas por microscopia óptica (Figura 5 a, b, c, d) pode-se observar a diferença de morfologia da face das amostras sem contato com a ferramenta (face externa), comparativamente à face interna das amostras, as quais tiveram contato com a ferramenta durante o processo de estampagem incremental (Figura 5 e,f,g,h). As amostras da face interna (Figura 5 e,f,g,h) apresentaram arrancamento de material e elevada deformação da superfície gerada pelo contato com a ferramenta durante o processo.
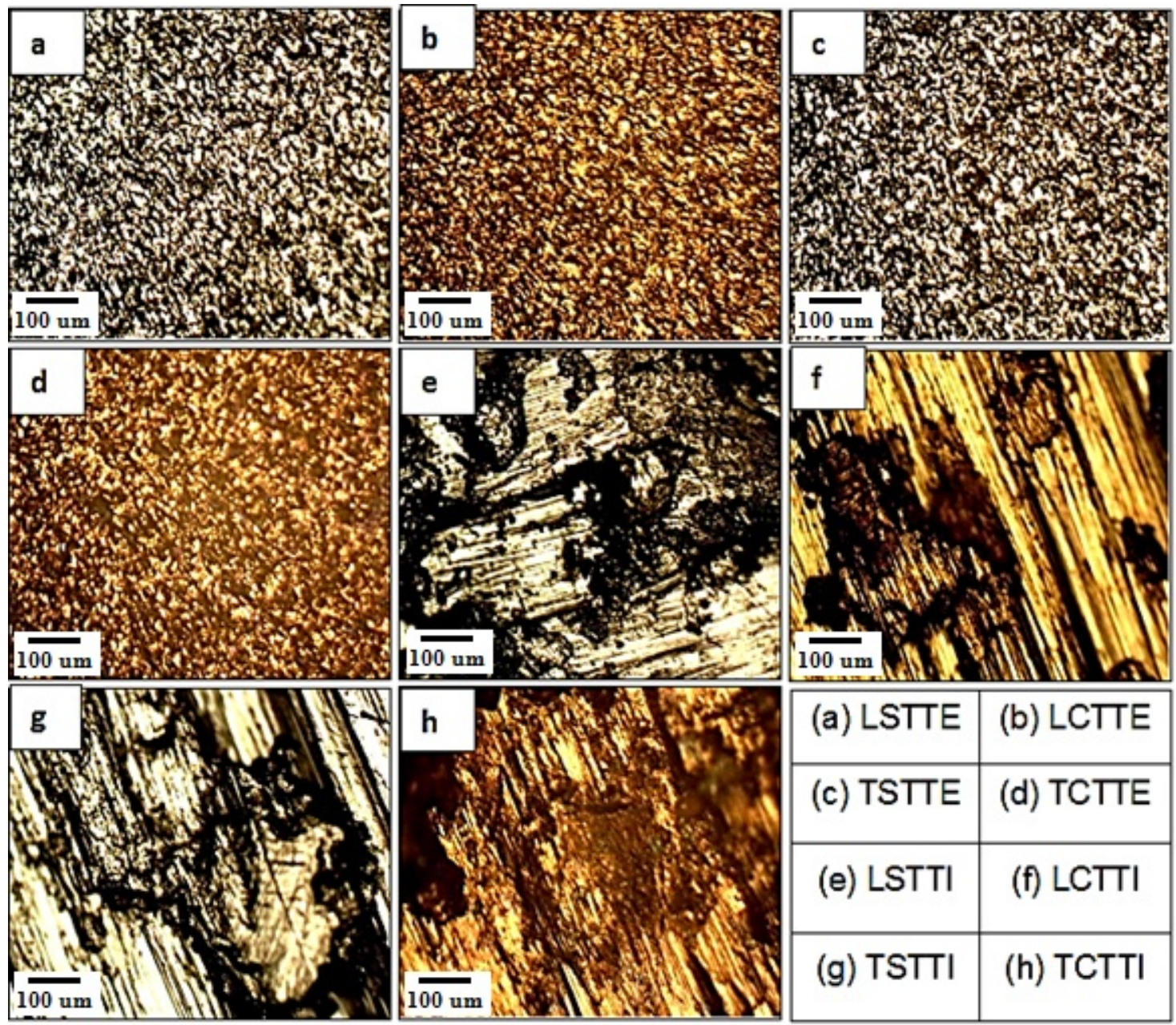

\begin{tabular}{|l|l|}
\hline (a) LSTTE & (b) LCTTE \\
\hline (c) TSTTE & (d) TCTTE \\
\hline (e) LSTTI & (f) LCTTI \\
\hline (g) TSTTI & (h) TCTTI \\
\hline
\end{tabular}

Figura 5. Imagens por Microscopia Óptica referente a superfície de todos os sistemas avaliados. 
O tratamento térmico também influencia na rugosidade das amostras (Tabela 2 e Figura 6). É possível observar uma diminuição da rugosidade superficial após tratamento térmico para a face interna. Isso ocorreu provavelmente devido ao efeito nivelador da camada de óxido formada sobre a superfície após o tratamento térmico (Figura 4c, d). Como já foi mencionado por outros autores [14,15], o tratamento térmico do Ti-cp ao ar promove o aumento da espessura da camada de óxido de Ti. $\mathrm{O}$ arrancamento de material pode ter influenciado sobre o aumento da rugosidade da face interna (Tabela 2 e Figura 6).

Os valores de rugosidade para a superfície externa, com e sem tratamento térmico, são menores e com pouco desvio (Tabela 2 e Figura 6), o que comprova um aspecto mais regular já observado por microscopia óptica (Figura 5 a, b, c, d). Maiores valores de rugosidade para superfície interna, comparativamente à superfície externa confirmam o aspecto irregular observado na (Figura 5 e,f,g,h).

Tabela 2. Medidas de rugosidade micrométrica $(\mu \mathrm{m})$ por perfilometria de contato.

\begin{tabular}{cccc}
\hline \multirow{2}{*}{ Amostras } & \multicolumn{3}{c}{ Rugosidade $(\mu \mathrm{m})$} \\
\cline { 2 - 4 } & $\mathrm{Ra}$ & $\mathrm{Rt}$ & $\mathrm{Rms}$ \\
\hline LSTTE & $1,38 \pm 0,20$ & $8,37 \pm 0,24$ & $1,73 \pm 0,20$ \\
TSTTE & $1,59 \pm 0,14$ & $9,47 \pm 1,06$ & $1,96 \pm 0,13$ \\
LCTTE & $1,11 \pm 0,06$ & $6,17 \pm 0,36$ & $1,34 \pm 0,07$ \\
TCTTE & $1,28 \pm 0,18$ & $8,57 \pm 1,52$ & $1,62 \pm 0,21$ \\
LSTTI & $3,54 \pm 0,72$ & $21,36 \pm 8,73$ & $4,92 \pm 1,59$ \\
TSTTI & $3,63 \pm 0,97$ & $18,77 \pm 8,82$ & $4,60 \pm 1,64$ \\
LCTTI & $2,76 \pm 0,90$ & $13,13 \pm 2,94$ & $3,29 \pm 0,95$ \\
TCTTI & $2,28 \pm 0,35$ & $9,49 \pm 0,56$ & $2,60 \pm 0,34$ \\
\hline
\end{tabular}

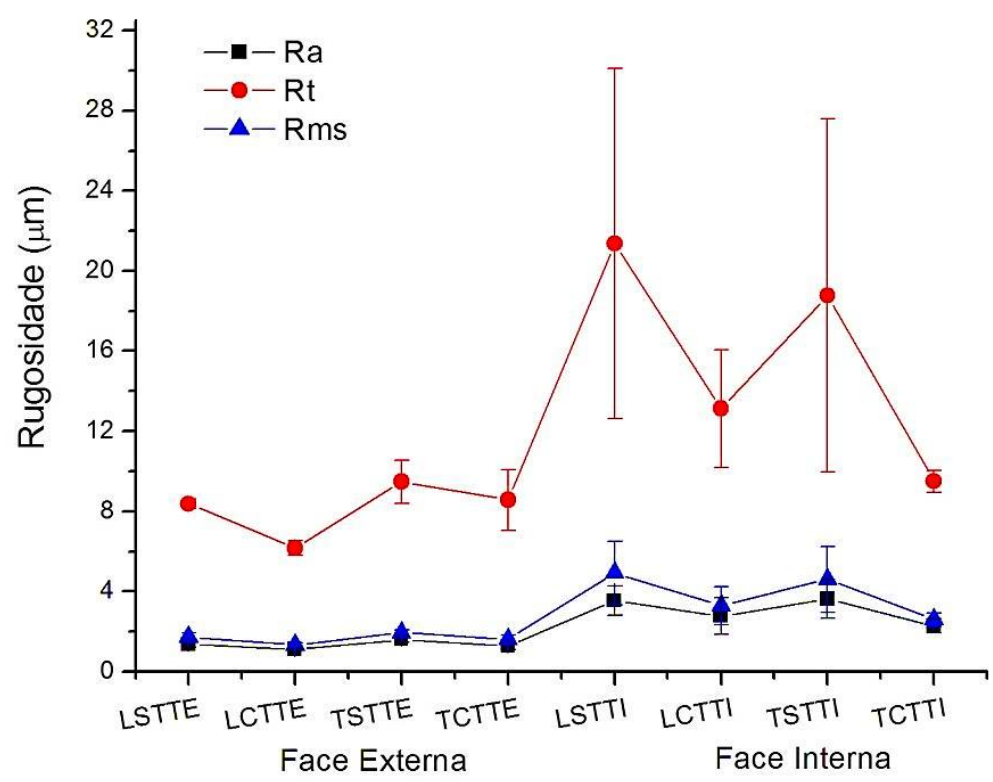

Figura 6: Relação entre Ra, Rms e Rt $(\mu \mathrm{m})$ da face externa e interna das amostras com e sem tratamento térmico. 
A partir da Tabela 3 e da Figura 7 é possível observar os valores dos ângulos de contato determinados para as amostras utilizando a solução Kokubo [12]. Para todas as amostras observou-se um valor de ângulo de contato menor que $90^{\circ}$, Contudo, todas as amostras da face externa sem tratamento térmico apresentaram maiores valores de ângulo de contato, comparativamente à face interna. Como a face interna é mais rugosa (Tabela 2 e Figura 6), esperava-se que isso contribuísse para o aumento da molhabilidade, ou seja, diminuição do ângulo de contato. De acordo com a literatura, um aumento dos valores de rugosidade em ordem micrométrica tende a ocasionar uma diminuição dos valores de molhabilidade $[16,17]$.

De um modo geral, independentemente da amostra, o tratamento térmico promoveu a diminuição dos valores de ângulo de contato, indicando um aumento do caráter hidrofílico. Esse comportamento pode estar associado ao caráter hidrofílico do óxido de $\mathrm{Ti}$ que se forma no tratamento térmico ao ar. Um estudo [18] envolvendo tratamento superficial de Ti-cp mostrou que o aumento da rugosidade ocasionou uma diminuição nos valores de ângulo de contato (superfície mais hidrofílica). Este mesmo estudo mostrou que o aumento da rugosidade favoreceu a formação do osso no início do processo de cicatrização. Outro estudo [19] observou maior formação óssea em implantes de superfícies mais rugosas.

Tabela 3. Medidas de ângulo de contato.

\begin{tabular}{cccc}
\hline Amostra & $\begin{array}{c}\text { Solução } \\
\text { KOKUBO }\end{array}$ & Amostra & $\begin{array}{c}\text { Solução } \\
\text { KOKUBO }\end{array}$ \\
\hline LSTTE & $78^{\circ} \pm 5$ & LSTTI & $53^{\circ} \pm 6$ \\
TSTTE & $73^{\circ} \pm 7$ & TSTTI & $39^{\circ} \pm 1$ \\
LCTTE & $50^{\circ} \pm 2$ & LCTTI & $55^{\circ} \pm 5$ \\
TCTTE & $46^{\circ} \pm 3$ & TCTTI & $35^{\circ} \pm 1$ \\
\hline
\end{tabular}

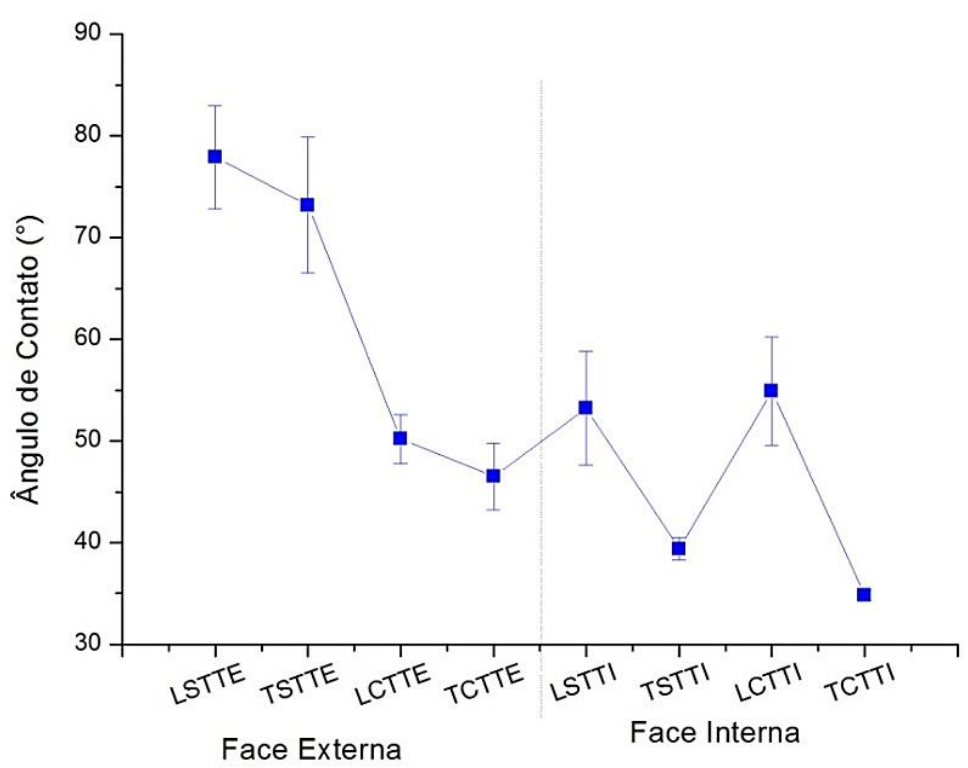

Figura 7. Molhabilidade da face interna e face externa em solução Kokubo.

Não foi observada infuencia do sentido de laminação da chapa sobre a molhabilidade e rugosidade das amostras. 
Da Figura 8 até Figura 11 estão apresentadas as imagens de MEV-EDS para as amostras de face interna e face externa somente sem tratamento térmico. As imagens das amostras com tratamento termico não foram apresentadas neste trabalho, ja que não foi verificada nenhuma alteração morfológica das superfícies após o tratamento.

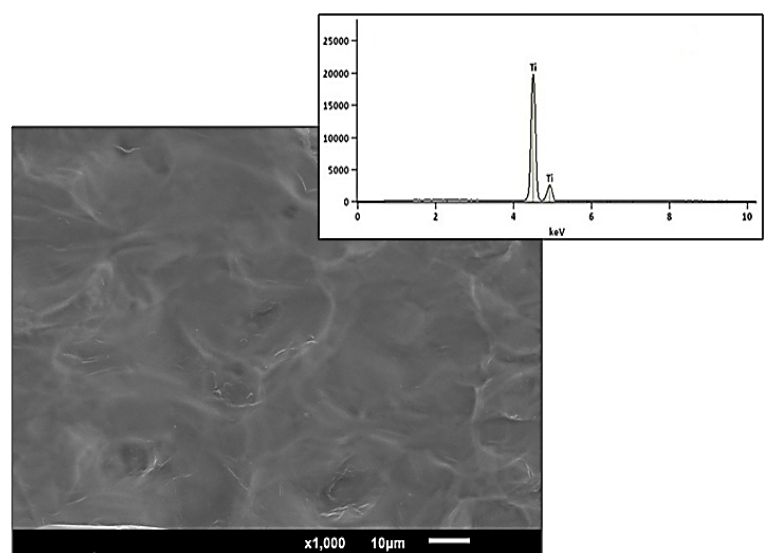

Figura 8. Amostra de face externa, sem tratameno térmico, longitudinal a direção de laminação (LSTTE).

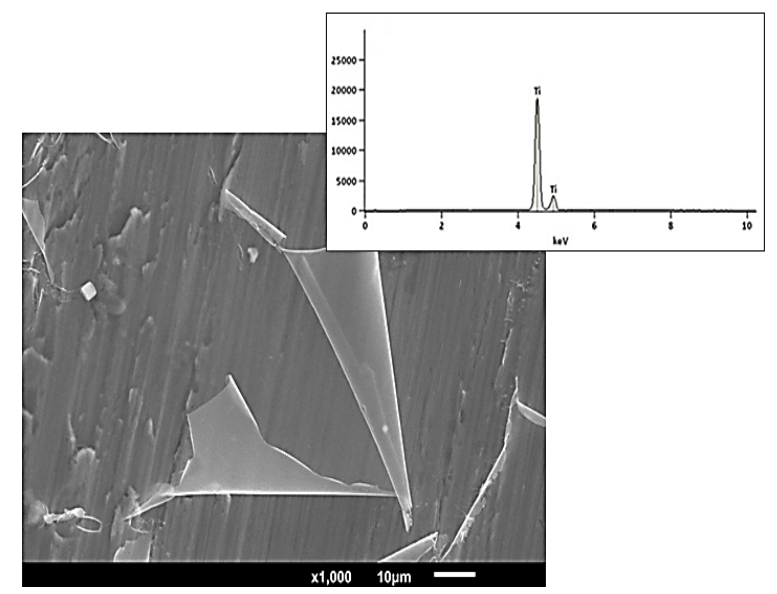

Figura 10. Amostra de face interna sem tratamento térmico, longitudinal a direção de laminação (LSTTI).

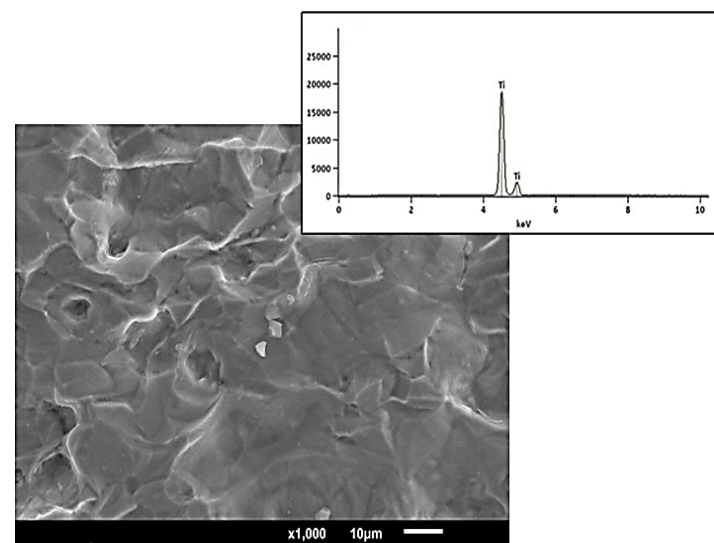

Figura 9. Amostra face externa, sem tratamento térmico, transversal a direção de laminação (TSTTE).

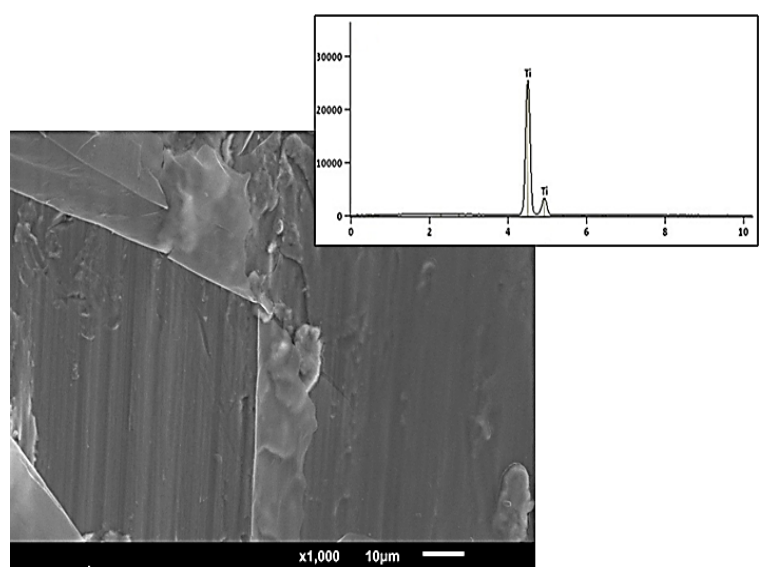

Figura 11. Amostra de face interna sem tratamento térmico, transversal a direção de laminação (TSTTI).

A partir das imagens por EDS não foi possível detectar a presença de qualquer outro elemento químico diferente do Ti, conforme observado (Figura 8 a Figura 11). Isso indica que não houve incorporação do lubrificante à superfície estampada, como foi mencionado anteriormente, o lubrificante é um óleo sintético que contém lítio.

Além disso, conforme mostrado na Figura 10 e Figura 11, a face em contato com a ferramenta mostrou que o processo de estampagem incremental promoveu o arrancamento de material da superfície e a ruptura de camadas de material. Este arrancamento de material pode ter favorecido o aumento dos valores de rugosidade da face interna (Tabela 2), o que também pode ser identificado pelas regiões escuras conforme visto por análises de microscopia óptica (Figura 4e, Figura 4g), correspondendo ao material da superfície que esteve em contato com a ferramenta em processo de estampagem, o qual sofreu arrancamento e posteriormente foi incorporado na superfície. 
Esse estudo mostrou que entre as faces avaliadas, a face que apresenta a superfície que melhor favoreceria o processo de osseointegração corresponde à face interna com tratamento térmico. Pois estas mostraram menores valores de rugosidade micrométrica e uma superfície mais hidrofílica. Como já demonstrado por outros autores, superfícies com menores valores de rugosidade micrométrica ou mais próximo de $1 \mu \mathrm{m}[20,21]$ e superfícies mais hidrofílicas [22] promovem uma maior adesão celular e proliferação de osteoblastos e fibroblastos.

\section{CONCLUSÃO}

O processo de estampagem incremental promoveu o arrancamento e ruptura de camadas da superfície interna da chapa estampada.

O tratamento térmico contribuiu para a diminuição do ângulo de contato e da rugosidade das amostras, devido à formação de uma camada de óxido de titânio sobre a superfície.

As amostras de face interna apresentaram-se mais hidrofílicas do que as amostras de face externa.

Não foi observada influência do sentido de laminação da chapa sobre a molhabilidade e rugosidade das amostras

A partir da análise por MEV/EDS não foi possível detectar qualquer outro elemento químico diferente do $\mathrm{Ti}$, isso indica que não houve incorporação do lubrificante à superfície estampada.

Esse estudo mostrou que entre as faces avaliadas, a face que apresenta a superfície que melhor favoreceria o processo de osseointegração corresponde à face interna com tratamento térmico. Pois estas apresentaram menores valores de rugosidade micrométrica e uma superfície mais hidrofílica.

\section{Agradecimentos}

O presente trabalho foi realizado com o apoio da Capes, entidade do Governo Brasileiro voltada para a formação de recursos humanos, do CNPq e da Fapergs.

\section{REFERÊNCIAS}

1 Rupp, F.; Scheideler, L.; Rehbein, D.; Axman, D. and Geis-Gerstorfer. Roughness induced dynamics changes of wettability of acid etched titanium implant modifications. Biomaterials. 2004; 25, 1429-1438.

2 Huang, C. A.; Hsu, F. and Yu, C. H. Electropolishing behaviour of pure titanium in sulphuric acid-ethanol electrolytes with an addition of water. Corrosion Science. 2011, 2, 53, 589-596.

3 Boyan, B.D.; Batzer, R.; Kieswetter, K.; Liu, Y., Cochran, D.L.; Szmuckler-Moncler, S.; Dean, D.D. and Schwartz, Z. Titanium surface roughness alters responsiveness of MG63 osteoblast-like cells to 1a,25-(OH)2D3. Journal of Biomedical Materials Research. 1998; 39, 77-85.

4 Bauer, S.; Schmuki, P.; Mark, K. and Park, J. Engineering biocompatible implant surfaces Part I: Materials and surfaces. Progress in Materials Science. 2013; 58, 261326.

5 A. Georgi, F. Grinnel, T. Groth. Studies on the biocompatibility of materials: fibroblast reorganisation of substratum-bound fibronectin on surfaces varying in wettability. J. Biomed. Mater. Res. 1996; 30 385- 391.

6 Williams, D. F. Dictionary of biomaterials. Liverpool: Liverpool University Press, 1999.

7 Kasemo, B.; Lausmaa, J. Aspects of surface physics on titanium implants. Swedish Dental Journal Supplement, v. 28, pp. 19-36, 1985. 
8 Zhu, X.; Chen, J.; Scheideler, L.; Reichl, R.; Geis-Gerstorfer, J. Effects of topography and composition of titanium surface oxides on osteoblast responses. Biomaterials, $\mathrm{n}$. 18, v. 25, pp. 4087-4103, 2004.

9 Botticelli, D.; Berglundh, T.; Buser, D.; Lindhe, J. The jumping distance revisited. An experimental study in the dog. Clin. Oral Impl. Res., n. 1, v. 14, pp. 35-42, 2003.

10 Gil, L. M.; Ladeira, T. C.; Menezes, G. C.; Costa, F.; Silva F. The cell-extracellular matrix-biomaterial interface and the biocompatibility of titanium implants. Innov. Implant. J. Biomater. Esthet., v. 4, n. 3, p. 58-64, 2009.

11 P. Rodriguez. Incremental Sheet Forming - Industrial Applications. 2006.

12 Kokubo T. and Takadama H. How useful is SBF in predicting in vivo bone bioactivity? Biomaterials. 2006; 27, 2907-2915.

13 Mardare, D.; Rusu, G. I. The influence of heat treatment on the optical properties of titanium oxide thin films. Materials Letters. 2012; n. 56, pp. 210-214.

14 Rodrigo, L. S. Tribologia. 2004; Universidade Federal de Santa Catarina.

15 Kenneth G. Budinski. Tribological properties of titanium alloys. 1991; Wear, 151, 203217.

16 Nicolaiewsky, F. Escoamento de Líquido e Geração de Área Superficial em Recheios Estruturados. Doctoral Thesis. 1999; Escola de Química/UFRJ.

17 K.J. Kubiak, M.C.T. Wilson and T.G. Mathia, Ph. Carval. Wettability versus roughness of engineering surfaces. Wear. 2011; 271, Issues 3-4,523-528.

18 Elias, C. N.; Oshida, Y.; Lima, J. H. C.; Muller, C. M. Relationship between surface properties (roughness, wettability and morphology) of titanium and dental implant removal torque. Journal of the Mechanical Behavior of Biomedial Materials, v. 1, pp. 234-242, 2008.

19 Suzuki, K., Aoki, K., Ohya, K., 1997. Effects of surface roughness of titanium implants on bone remodeling. Bone 21, 507.

20 Rosa, A.L.; Belotti, M.M. Effect of cpTi surface roughness on human bone marrow cell attachment proliferation and differentiation. Braz. Dent. Journal. 2003; 14, 16-21.

21 X. Zhu, J. Chen, L. Scheideler, R. Reichl, J. Geis-Gerstorfer. Effects of topography and composition of titanium surface oxides on osteoblast responses. Biomaterials. 2004; 18 , 25, 4087-4103.

22 T.G. Ruardy, J.M. Schakenraad, H.C. Van der Mei, H.J. Busscher. Adhesion and spreading of human skin fibroblasts on physocochemically characterized gradient surfaces. J. Biomed. Mater. Res. 1995; 29, 1415-1423. 